\title{
The Pricing of Illiquidity as a Characteristic and as Risk
}

\author{
Yakov Amihud \\ New York University, USA \\ Haim Mendelson \\ Stanford University, USA
}

\begin{abstract}
This paper reviews research on the effects of different measures of liquidity on asset prices. The foundation is the pricing of liquidity as an asset characteristic that began with the theoretical model and empirical evidence of Amihud and Mendelson (1986). The positive relation between expected returns on financial assets and the illiquidity of these assets has since been reconfirmed both in the U.S. and worldwide. The positive relation between illiquidity and expected return gives rise to research on the effect of liquidity-related systematic risk. Two types of such risk are shown to be priced: exposure to shocks in market liquidity and exposure to the market illiquidity return premium. The pricing of these risks is stronger in times of greater funding illiquidity and economic stress.
\end{abstract}

Keywords: liquidity; asset pricing; system risk; Amihud measure

\section{Introduction}

The classic theory of asset pricing posits that the expected returns on financial assets are increasing in their risk because of investors' risk aversion. For individual assets, the Sharpe-Lintner-Mossin Capital Asset Pricing Model (CAPM) proposes that it is only the systematic risk that is priced, while the idiosyncratic risk is not priced because it can be diversified away. The empirical support for this theory for stocks is weak: it is hard to find evidence that a stock's systematic risk is

* We thank the editor, Panayiotis Andreou, for his comments.

(Multinational Finance Journal, 2015, vol. 19, no. 3, pp. 149-168)

(C) Multinational Finance Society, a nonprofit corporation. All rights reserved. DOI: $10.17578 / 19-3-1$ 
significantly priced. ${ }^{1}$ Further, Ang Hodrick, Xing and Zhang (2006, 2009) show that stock expected return is a declining function of the stock's idiosyncratic risk and of its exposure (or sensitivity to) the overall market risk.

Another theory of asset pricing, introduced by Amihud and Mendelson (1986), proposes that expected returns are an increasing function of assets' illiquidity or trading costs, because investors price assets so as to be compensated for these costs. The empirical evidence supports this theory. Studies have been done for stocks, both in the U.S. and worldwide (in one study, the pricing of liquidity is tested in 45 countries) for bonds and for derivatives, using a variety of measures of illiquidity. The evidence consistently shows that less liquid assets generate higher returns on average after controlling for asset characteristics and risk.

The Amihud-Mendelson (1986) theory on the positive relation between expected return and illiquidity also explains the well-known "equity premium puzzle" due to Mehra and Prescott (1985). The theory of asset pricing based on risk aversion alone cannot explain the large difference between the average return on equity, which is risky, and the return on the riskless Treasury bills, unless it is assumed that investors' risk aversion is unreasonably high. However, stocks (equity claims) are not only riskier than Treasury bills, but also far less liquid. ${ }^{2}$ The average transaction costs on stock trades is far larger than they are on Treasury bills, and bills can be traded in large blocks of tens of millions of dollars in a single transaction without affecting their price. Thus, by the Amihud-Mendelson (1986) theory, the differential return between stocks and bills is partly compensation for illiquidity in addition to it being compensation for risk. Consequently, it is unnecessary to assume high risk aversion to explain the observed equity premium, and there is no longer a puzzle.

The positive relation between expected return and illiquidity is the foundation for a more recent research track on the pricing of liquidity.

1. A recent article by Bali, Engle and Tang (2014) finds that the CAPM systematic risk is significantly priced, using dynamic conditional beta estimated from daily stock returns.

2. For example, Amihud and Mendelson (1991) report that the average bid-ask spread on Treasury bills was $0.008 \%$ and on short-term Treasury bonds it was $0.03 \%$, while the average bid-ask spread on the portfolio of the most liquid stocks in Amihud and Menselson's (1986) study was about $0.5 \%$, over 60 times greater than on Treasury bills and about 17 times greater than on bonds. 
If liquidity matters - i.e., if the level of liquidity is priced - exposure to shocks in liquidity should matter as well. In these studies, market liquidity is a systematic factor whose shocks are transmitted to affect the prices of individual assets and thus the price exposure of individual assets to the market-wide liquidity shocks is priced. In addition, if market return affects each asset's liquidity level, which in turn affects its expected return, then the extent of this effect of market return on asset liquidity is another component of systematic risk which should be priced. These are all hypotheses that are tested in a number of empirical studies, using data from the U.S. and other countries. The results are generally consistent with the hypotheses above.

The liquidity-related systematic risk of assets is also studied in a different way. Variations in individual stock returns, which reflect variations in both risk premium and liquidity premium, may vary as the market-wide risk premium and liquidity premium vary. Here, the systematic risk is measured not with respect to variations in the market-wide level of liquidity but with respect to variations in the market-wide liquidity return premium - which given the initial work of Amihud and Mendelson (1986), is positive and varies with the level of liquidity and with investors' preference or valuation of liquidity. This is analogous to the common study of the market systematic risk with respect to the market risk premium or excess return over the risk-free rate, which varies with the market's level of risk and with investors' risk aversion as well.

An interesting feature of the pricing of liquidity risk is that it is conditional on the state of the market. The evidence reviewed below shows that the risk of exposure to shocks in illiquidity and the illiquidity return premium are valued more in times of financial market stress and lower funding liquidity.

Below, we review the evolution in research of the pricing of liquidity that begins with the pricing of liquidity as a characteristic and proceeds with the study of the pricing of liquidity systematic risk.

\section{The pricing of illiquidity as characteristic}

In Amihud and Mendelson's model, investors wish to maximize the expected present value of the cash flows generated by the securities in their portfolio, assuming that each security generates a riskless flow of dividend and incurs some liquidation cost. Investors are risk neutral, 
they are subject to random arrival of a need to liquidate their asset, and they differ in their time horizon to liquidation. In equilibrium, the required return is an increasing function of the asset's illiquidity costs because investors require a compensation for bearing these costs. The model predicts that this positive expected return illiquidity costs relation is concave because of the liquidity clientele effect. Less liquid assets are held in equilibrium by investors with longer investment horizons who effectively "amortize" their liquidity costs over a longer period. Thus, the liquidity costs per period are lower and the resulting marginal increase in required return is smaller as one moves toward increasingly less liquid assets.

Formally, Amihud and Mendelson propose that asset $j$ return to an investor $k, r_{j, k}$ is the gross return on the asset, $R_{j}$, minus the expected liquidation cost, $\mu_{k} S_{j}$, where $\mu_{k}$ is the probability of liquidation within the unit time and $S_{j}$ is the proportional liquidation costs, $r_{j, k}=R_{j}-\mu_{k} S_{j}$. We naturally observe the gross return $R_{j}$ and thus in equilibrium, for the equilibrium (unobserved) net return $r_{j, k}^{*}$,

$$
R_{j}=r_{j, k}^{*}+\mu_{k} S_{j}
$$

The Amihud - Mendelson theory thus says that asset illiquidity (in this model, proxied by $S_{j}$ ) is a priced characteristic. In equilibrium, asset expected returns are an increasing function of illiquidity. Amihud and Mendelson test the theory using data on stocks traded in the NYSE between 1960 and 1980 (Amihud and Mendelson, 1986, 1989). The results show that across stock portfolios sorted on illiquidity and risk, average stock return is an increasing function of the stock bid-ask spread - a measure of illiquidity cost - after controlling for systematic and unsystematic risk. Amihud and Mendelson (1986) also prove the existence of liquidity clientele, by which frequent traders (those with high $\mu_{k}$ ) prefer to invest in the more liquid assets - those with the lower $S_{j}$ - whereas the low-frequency investors opt for the less liquid assets (those with the lower $S_{j}$ ) because they can depreciate the transaction costs over longer period. Thus in equilibrium, the $R-S$ positive relation is increasing and concave.

Importantly, Amihud and Mendelson show that the rise in expected return as a function of illiquidity cost, depreciated by the investor holding period goes beyond mere compensation for these costs. Instead, investors earn in equilibrium an illiquidity premium that exceeds the 
compensation for the expected cost of illiquidity. That is the net-of-cost return on an asset must be higher than the net-of-cost return on the asset which is next to it in terms of lower cost. In terms of model (1), $r_{j, k}^{*}$ increases as a function of $S_{j}$.

Of course, the two theories of asset pricing may coexist. Expected return may be an increasing function of both the asset's risk and its illiquidity cost.

The empirical support for the Amihud-Mendelson (1986) asset pricing theory is quite robust; it is reviewed in Amihud, Mendelson and Pedersen $(2005,2013)$. In addition to the evidence in Amihud and Mendelson (1986), Brennan and Subrahmanyam (1996) and Amihud (2002) show that there is a positive and significant relation across stocks between expected return and illiquidity, using other measures of illiquidity costs. Brennan and Subrahmanyam use Kyle's (1985) measure of illiquidity which is the price impact of orders, obtained from intraday estimates using data on transactions and quotes. Their analysis also provides an estimate of the fixed cost of transacting which is unrelated to the quantity traded. They find that both cost components the price impact and the fixed cost - are priced. Amihud measures illiquidity by the ratio of absolute daily return to daily (dollar) volume, denoted ILLIQ, which emulates Kyle's price impact measure. This measure estimates how much trading it takes to move the stock price by one unit. Datar, Naik and Radcliffe (1998) measure stock liquidity by the stock turnover (share trading volume relative to the number of shares outstanding). In Amihud and Mendelson's (1986) equilibrium, stock illiquidity cost is negatively correlated with the stock's trading frequency per period, which can be proxied by turnover. Using equation (1), they prove that in equilibrium, stocks with high bid-ask spread $S_{j}$ are allocated to investors with lower trading frequency $\mu_{k}$, which they call "the clientele effect." A proxy for the trading frequency $\mu_{k}$ is turnover. Datar et al. (1998) find that stock expected return is significantly declining in the stock's turnover. A number of other studies find a positive relation between expected return and illiquidity; see Amihud, Mendelson and Pedersen (2005, 2013).

The empirical studies on the pricing of illiquidity mostly employ U.S. data. Amihud, Hameed, Kang, and Zhang (2015) provide international evidence on the positive relation between expected return and illiquidity, using data from 45 countries divided into 26 developed and 19 emerging markets. The data cover 22 years, 1990-2011 (for most countries). For each country, they construct a factor of 
illiquid-minus-liquid stocks (denoted $I M L$ ), using the extreme quintile portfolios of stocks ranked by the Amihud's (2002) measure, and then regress $I M L$ on Fama and French's (1993) factors: the market's excess return, the return on small-minus-big stocks and the returns for high-minus-low book-to-market stocks. There are six such factors: three global factors and three regional factors which are matched with the country in that region. The alpha (intercept) from a regression of the country's $I M L$ on these six common risk factors measure the risk-adjusted excess return due to illiquidity.

Amihud Hameed, Kang and Zhang (2015) find that illiquid stocks outperform liquid stocks in nearly all countries. The risk-adjusted illiquidity monthly premium alpha is $0.82 \%, 0.45 \%$ or $0.73 \%$, respectively, for portfolio returns that are return weighted, ${ }^{3}$ value weighted or volume weighted. ${ }^{4}$ Furthermore, alpha is positive for $84 \%$, $67 \%$ and $80 \%$ of the countries, using respectively the three weighting methods, significantly higher than the chance result of $50 \%$. In another test, Amihud et al. (2015) do a cross-section regression in each country of monthly stock returns on lagged stock illiquidity (using Amihud's measure) and other stock characteristics (size, book-to-market, return volatility, market risk and past return to capture momentum). Again, the results show that the average of the cross-sectional coefficient of illiquidity is positive in $79 \%$ of the countries, and its average across countries is positive and significant. These results show that illiquidity is positively and significantly priced around the world.

Amihud et al. (2015) also find that there is cross-country commonality in the illiquidity return premium $I M L$, after controlling for the six global and regional Fama-French (1993) return factors. This is different from the commonality in the level of illiquidity (or shocks to illiquidity) that are documented for the U.S. by Chordia, Roll, and Subramanyam (2000), Hasbrouk and Seppi (2000) and Huberman and Halka (2001), and shown by Brockman, Chung, and Perignon (2009) and Karolyi, Lee, and van Dijk (2012) to exist in other countries. Lee

3. Return weighting is done following the suggestion of Asparouhova, Bessembinder and Kalcheva $(2010,2013)$. It is similar to equally-weighted portfolio returns with the returns weighted by past returns, in order to mitigate the bias in the calculation of average returns resulting from noise in returns, which may result from microstructure effects.

4. Volume weighting is done because in many countries outside the U.S. and the U.K., where ownership in companies is concentrated in the hands of one or a few entities, the float is much smaller than the market value of the stock. The trading volume is then more strongly related to the float than the market value. 
(2011) shows that there is commonality in illiquidity across countries. The commonality documented by Amihud et al. (2015) is different: it is in the liquidity return premium, not in illiquidity itself.

Using each country's $I M L$ series, Amihud et al. construct global and regional factors of $I M L$. Then they regress each country's $I M L$ on the global and regional $I M L$ which excludes that country's own series, as well as on the six Fama-French return factors. They find that the coefficients of the global and regional $I M L$ are positive for at least $80 \%$ of the countries, significantly higher than the $50 \%$ chance result, and their average is positive, significantly greater than zero. The study finds that the cross-country commonality in the illiquidity return premium is stronger in countries with markets that are open to foreign investors. This is because following the model of Brunnermeier and Pedersen (2009), changes in the illiquidity premium are related to changes in the shadow cost of illiquidity, resulting from financial constraints. Thus, in markets that are financially linked, these constraints are also likely to move together, which generates commonality in the illiquidity premium. Amihud et al. also find that following the adoption of the Euro as a common currency, the commonality in illiquidity among the countries that adopted the Euro increased.

In summary, following the theory of Amihud and Mendelson(1986), evidence shows that expected return is an increasing function of asset illiquidity because investors want to be compensated for holding less liquid assets. This compensation is different from the compensation that investors require for bearing risk about asset value.

\section{The pricing of systematic illiquidity risk}

Illiquidity varies greatly over time. Figure 1 presents the monthly $\log (I L L I Q)$. ILLIQ, a proxy for market illiquidity, is the Amihud's (2002) illiquidity ratio, averaged across stocks (using value weighting) for all NYSE and AMEX stocks (CRSP codes 10 and 11) excluding stock days with stock trading volume of less than 100 shares and excluding stocks priced below $\$ 5$. Also, $1 \%$ of the extreme observations are excluded every day.

Panel A shows the strong decline in ILLIQ since the early 1970s, and panel B shows in greater detail the market ILLIQ for the recent ten-year period 2005-2014. The rise in illiquidity during the 2008-2009 crisis is quite strong but illiquidity was lower at the end of 2014 than 
A. The level of $\log (I L L I Q), 1950-2014$

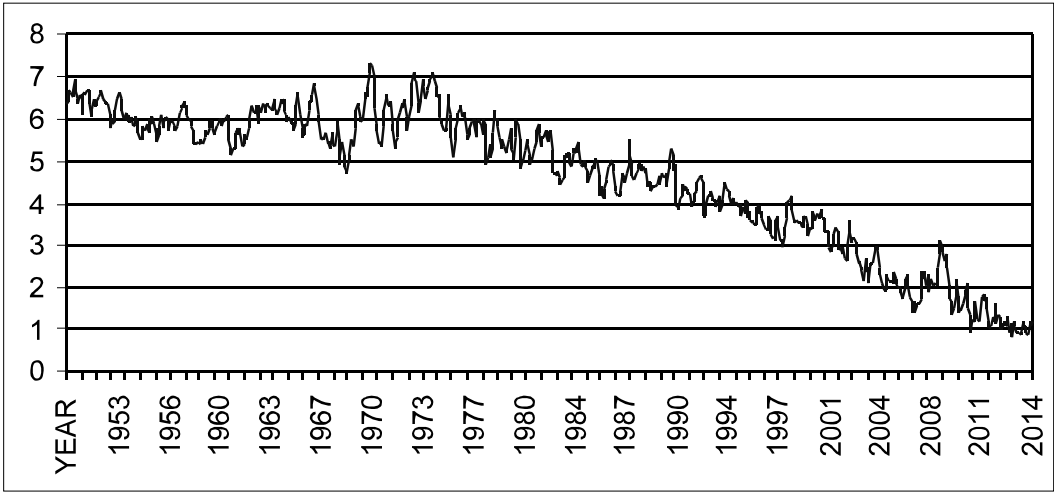

B. Level of $\log (I L L I Q)$ over the last 10 years, 2005-2014

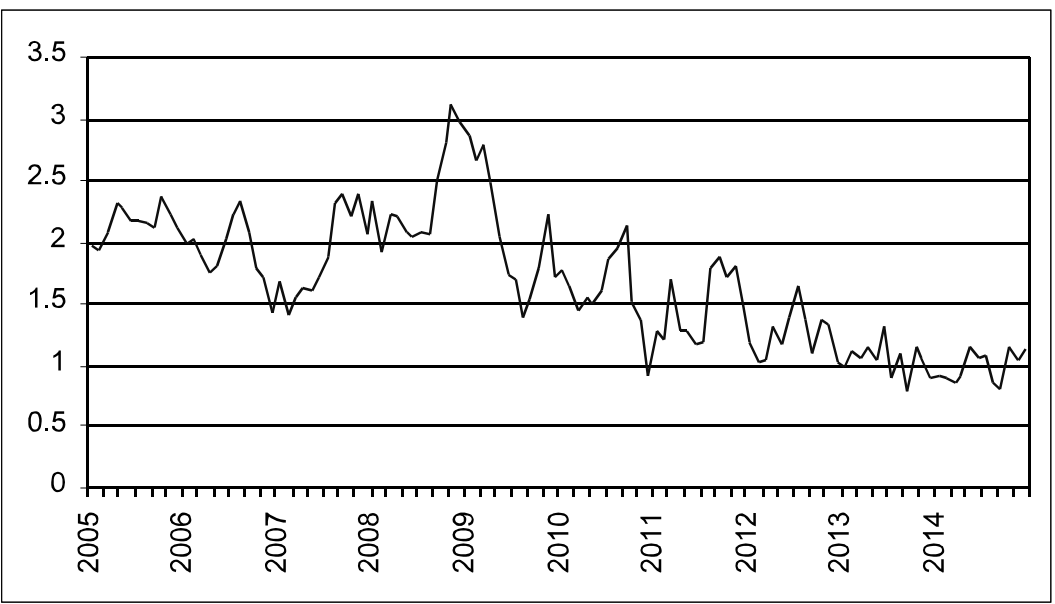


C. First difference in $\log (I L L I Q), 2005-2014$

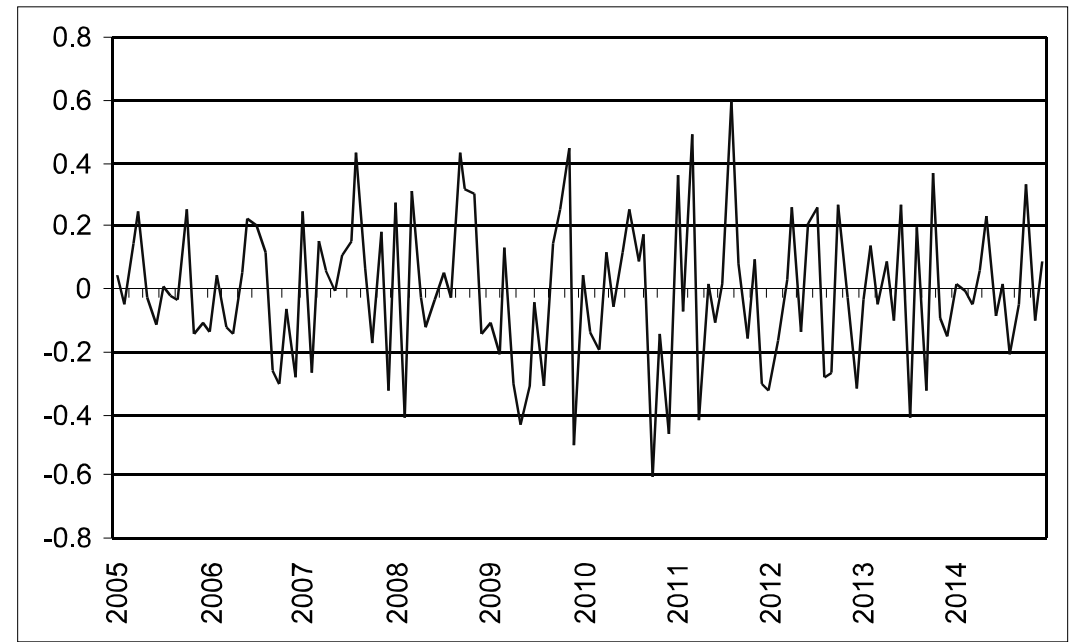

FIGURE 1.- The monthly $\log (I L L I Q)$

Note: ILLIQ is the ratio of daily absolute return to daily absolute volume (in dollars), see Amihud (2002). The average across stocks is value weighted. The numbers are adjusted such that the mean of 2014 equals 1.

ever before. The considerable variability in $I L L I Q$ is shown in panel $\mathrm{C}$ which presents the first difference in $\log (I L L I Q)$.

The general decline in illiquidity over the recent decades may explain in part the rise in the stock market prices. By the Amihud-Mendelson (1986) theory, investors require lower expected returns on equity claims (relative to Treasury bills, which have the greatest liquidity) when the illiquidity of these claims is lower. This means that for any given cash flows that the stocks generate - in terms of level, risk and growth expectations - the stock value should be higher when illiquidity falls. This is what we have generally witnessed since the end of the early 1980 s.

The plots show quite clearly that illiquidity varied significantly over time. Amihud (2002) suggests that these variations should affect stock values because illiquidity is persistent. The first-order autoregressive coefficient of $\log (I L L I Q)$ is about 0.95 , which means that a rise or fall in illiquidity is likely to persist for a considerable period of time. When illiquidity rises, investors demand higher expected return which means that they discount future cash flows at a higher rate. If illiquidity is 
unlikely to affect the stocks' cashflow (or if the effect satisfies some conditions), the increased required return implies that stock prices should fall so the expected return rises. This implies a negative contemporaneous relation between shocks to market illiquidity and changes in stock prices, that is, a negative relation between illiquidity shocks and realized market returns. Amihud further shows that this negative relation between illiquidity shocks and stock returns is stronger for smaller, less liquid stocks. That is, illiquid stocks which usually have higher expected return also have greater sensitivity to liquidity shocks. ${ }^{5}$

Pastor and Stambaugh (2003) test across stocks the relation between the liquidity beta, $\beta^{L}$, or the sensitivity of stock returns to liquidity shocks, and expected stock return showing that expected return is increasing in $\beta^{L}$. They measure market liquidity following Campbell, Grossman and Wang (1993), as the (negative value of the) coefficient $\gamma_{j}$ of lagged dollar volume signed by the same day's stock return, in the following regression that is carried out for each stock $j$ :

$$
r_{j, d+1}^{e}=\theta_{j}+\varphi_{j} r_{j, d}+\gamma_{j} \operatorname{sign}\left(r_{j, d}^{e}\right) \cdot v_{j, d}+e_{j, d+1}
$$

where $r_{j, d}^{e}$ is the return on stock $j$ on day $d$ in excess of the market return and $v_{j, d}$ is the daily dollar volume. ${ }^{6}$ More negative $\gamma_{j}$ means lower liquidity. They find that $\gamma_{j}$ increases in firm size, as expected, since larger size means greater liquidity. ${ }^{7}$ Pastor and Stambaugh estimate $\gamma_{j, t}$ for each month $t$ and averaging it across stocks produces $\gamma_{t}$, the market liquidity in month $t$. Its innovations from an autoregressive model, $\Delta \gamma_{t}$, are then used to estimate each stock's exposure to liquidity shocks, $\beta^{L}$, obtained as the slope coefficient of the market innovations in liquidity in a regression model of daily stock returns that also including the three Fama-French (1993) factors. The predicted $\beta^{L}$ is obtained by using instrumental variables. Finally, stocks are sorted on their liquidity beta $\beta^{L}$ and divided into ten portfolios. Pastor and Stambaugh show that the differential return on the high-minus-low $\beta^{L}$ portfolio has positive and

5. Amihud (2002) also provides evidence that supports the use of the Amihud-Mendelson (1986) theory to explain the Mehra-Prescott (1985) equity premium puzzle. He shows that the equity premium - the market's excess stock return over Treasury bills - is partly explained by variations in market liquidity.

6. On a day of zero stock return, the volume obtains the sign of the market return.

7. However, Hasbrouck (2005) finds a small and unstable correlation between $\gamma_{j}$ and a measure of Kyle's $\lambda_{j}$ that is estimated from microstructure data. 
significant risk-adjusted return. That is, stocks with higher liquidity risk - higher $\beta^{L}$ - have higher expected return. This result is consistent with the evidence in Amihud (2002) that small-stock return which is on average higher than that on large stock, has higher exposure to illiquidity shocks.

Acharya and Pedersen's (2005) broad model of asset pricing proposes that the CAPM holds for net return, which equals the gross return minus transaction (liquidation) cost. The expected return of asset $j$ is formulated as $E\left(r_{j}\right)=\delta E\left(c_{j}\right)+\lambda\left\{\operatorname{Cov}\left(r_{j}-c_{j}, r_{m}-c_{m}\right) / \operatorname{Var}\left(r_{m}-c_{m}\right)\right\}$, where $c$ is liquidation costs and $\delta$ and $\lambda$ are constants reflecting the impact of expected trading costs on expected return and the market's price of risk, respectively. This gives rise to four $\beta s$. One is the standard CAPM $\beta$ the sensitivity of the stock return to the market return. Then, there are three liquidity-related $\beta s: \beta^{L 1}$ is the sensitivity of the stocks' illiquidity to the market's, $\beta^{L 2}$ is the sensitivity of the stock's return to the market's illiquidity - similar to the sensitivity estimated by Amihud (2002) and by Pastor and Stambaugh (2003) - and $\beta^{L 3}$ is the sensitivity of the stock's illiquidity to the market return. The respective signs of the averages of these $\beta$ s are positive, negative and negative. Finally, the (unconditional version of the) Acharya-Pedersen's CAPM model is:

$$
E\left(r_{t+1}^{i}\right)=r^{f}+\kappa E\left(c_{t+1}^{i}\right)+\lambda\left(\beta+\beta^{L 1}-\beta^{L 2}-\beta^{L 3}\right)
$$

where $r$ is the gross stock return, $c$ is the stock transaction cost and $\kappa$ adjusts for the difference between the average holding period and the monthly estimation period. The model is estimated employing ILLIQ (and its innovations) for NYSE/AMEX stocks, 1964-1999. Stock portfolios - 25 of them - are constructed by sorting stock on ILLIQ or on size. The evidence provides significant support for the liquidity-adjusted CAPM: $\lambda$ is positive and statistically significant, meaning that the liquidity systematic risk is priced. When the pricing of the three liquidity $\beta s$ is estimated separately, the most strongly priced is $\beta^{L 3}$. That is, the most importantly aspect of the liquidity risk is that of having the stock less liquid in "bad times", i.e., when the market declines. In this state of the world the marginal utility of consumption is higher because wealth and consumption decline, and having to pay more for trading the stock exacerbates the consumer's situation. ${ }^{8}$

8. Chordia, Subrahmanyam and Anshuman (2001) study the effect of total illiquidity 
De Jong and Driessen (2012) extend the analysis of Acharya and Pedersen (2005) on the pricing of (il)liquidity risk to the corporate bond market. They find that the annual liquidity risk premium is $0.6 \%$ and $1.5 \%$ for investment-grade and speculative-grade bonds, respectively.

In summary, if investors care about stock illiquidity to the extent that they demand higher expected returns on stocks which are more illiquid (Amihud and Mendelson (1986)), variations in stock illiquidity should affect stock value. Consequently investors not only prefer assets that are more liquid, they also prefer assets with smaller exposure to liquidity shocks. Investors prefer assets whose prices fall less when market illiquidity rises, assets whose illiquidity rises less with a rise in market illiquidity, and assets whose illiquidity rises less when there is a market-wide decline in prices. Empirical evidence supports these theoretical predictions.

\section{The pricing of conditional illiquidity risk}

Subsequent research shows that the extent to which liquidity systematic risk is priced depends on market conditions. Martinez, Nieto, Rubio and Tapia (2005) estimate a conditional liquidity-adjusted CAPM, where the liquidity $\beta$ is conditional on the aggregate book-to-market ratio in the economy. From $E_{t-1}\left[M_{t}\left(1+r_{j, t}\right)\right]=1$, they assume the price kernel $M_{t}=d_{0, t-1}+d_{1, t-1} r_{m, t}+d_{2, t-1} L_{t}, L_{t}$ being liquidity and $d_{k, t}=d_{k, 0}+d_{k, 1} b m_{t}$ for $k=0,1,2, b m_{t}$ being the aggregate book-to-market ratio. They denote $\beta_{j, x}=\operatorname{cov}\left(r_{j, t}, x_{t}\right) / \operatorname{var}\left(x_{t}\right)$ and $\beta_{j, x b m}=\operatorname{cov}\left(r_{j, t}, b m_{t-1} x_{t}\right) / \operatorname{var}\left(b m_{t-1} x_{t}\right)$ for $x=r_{m}$ or $L ; \beta_{j, L}$ is related to the liquidity beta of Pastor and Stambaugh and to $\beta^{L 2}$ of Acharya and Pedersen (2005). The innovation here is that this liquidity beta is made conditional on lagged $\mathrm{bm}$; rise in aggregate $b m$ implies adverse market conditions. It is expected that $\beta_{j, L}$ $<0$ and $\beta_{j, L b m}<0$. The pricing model is

$$
E\left(r_{j}\right)=\gamma_{0}+\gamma_{1} \beta_{j, m}+\gamma_{2} \beta_{j, b m}+\gamma_{3} \beta_{j, x b m}+\gamma_{4} \beta_{j, L}+\gamma_{5} \beta_{j, L b m}
$$

risk, not only the systematic risk. They estimate the cross-section pricing of stocks as a function of illiquidity and risk factors, the volatility of trading activity which measures liquidity, following Brennan, Chordia and Subrahmanyam (1998). They find that both the level of liquidity and the volatility of trading activity have a negative and significant effect on risk-adjusted stock returns. In this analysis, the sign of the effect of the total liquidity risk is the opposite of that of the systematic liquidity risk, documented above. 
Martinez, Nieto, Rubio and Tapia find that when using Amihud's (2002) ILLIQ for $L$, the coefficients $\gamma_{4}$ and $\gamma_{5}$ are negative and significant. This implies that the illiquidity $\beta$ is priced, and particularly so when the market's $b m$ ratio has risen, i.e., in times of adverse market conditions.

Watanabe and Watanabe (2008) study the pricing of illiquidity risk in the context of a regime-switching model which is made conditional on the market turnover. They find that illiquidity is significantly priced only in times of high turnover, which they interpret as times of problems in market liquidity.

The conditional pricing of liquidity risk of corporate bonds is studied by Acharya, Amihud and Bharath (2013), employing a regime-switching model. They employ two series of illiquidity: one is stock illiquidity which is the innovations in monthly stock market $I L L I Q$, and the other is the innovations in the average bid-ask spread of short-term Treasury bonds. They then use monthly returns of portfolios of corporate bonds, grouped by their rating. Chen, Lesmond and Wei (2007) show that corporate bond illiquidity increases monotonically when moving from safer bonds - bonds with higher rating - to riskier bonds, those with lower rating. Riskier bonds are more illiquid because for such bonds the asymmetric information problem, which gives rise to illiquidity (Bagehot (1971), Glosten and Milgrom (1985), Kyle (1985)) is exacerbated. Acharya, Amihud and Bharath use a four-factor model that includes the bond term premium, the bond risk or default premium - both measured in monthly bond returns - and the two illiquidity factors. They regress bond portfolio returns on these four factors and find that the $\beta$ of the two illiquidity factors declines monotonically as the credit rating of the bonds deteriorates and their illiquidity rises. This makes sense: for assets with greater illiquidity risk the illiquidity $\beta$ should be lower because when illiquidity rises, their price falls by more.

But these are the unconditional illiquidity $\beta$. Acharya, Amihud and Bharath then estimate the illiquidity risk in the context of a regime-switching model, following Hamilton (1994). This procedure divides the sample observations into two groups, where in each there is a possibly different estimation of the model. In this estimation, two bond portfolios are used, one of investment-grade bonds and one of speculative rating ("junk") bonds. The excess returns of these bond portfolios are regressed on the four factors described above. The result of this estimation procedure is that there are two regimes, 1 and 2 . In 
Regime 1, both illiquidity factors are barely priced - in fact, only the stock illiquidity factor is priced for junk bonds. However in Regime 2 both bond portfolios are strongly priced and in quite a peculiar way. The coefficients of the two illiquidity factors have negative and significant coefficients for junk bonds, and positive and significant coefficients for investment-grade bonds (it should be remembered that these coefficients are conditional on the general market effect which is captured by both the default term factors.) This indicates "flight to liquidity" when Regime 2 is in place. That is investors switch from junk bonds that are less liquid to the more liquid investment-grade bonds.

Acharya, Amihud and Bharath then examine the characteristics of these two regimes. They find that likelihood of Regime 2 is higher in times of macroeconomic distress or recession measured in a number of ways, low market liquidity measured by high TED spread and dealers' inventories coupled with high market volatility. That is the pricing of illiquidity varies over time as a function of the state of the economy. Acharya, Amihud and Bharath find the same pattern to hold for stock portfolios sorted on their book-to-market ratio, which they find to be related to their likelihood of default.

In summary, while liquidity risk is priced on average the pricing effect of illiquidity shocks varies as a function of business and financial conditions, being stronger in times of economic stress and capital funding illiquidity.

\section{The pricing of the systematic risk of the illiquidity return premium factor}

The two major studies of the systematic liquidity risk of stocks - Pastor and Stambaugh (2003) and Acharya and Pedersen (2005) - and the study of illiquidity risk in bonds by Acharya, Amihud and Bharath (2013), estimate asset security systematic risk with respect to innovations in market illiquidity. Instead, Liu (2006) and Amihud (2014) estimate the stock systematic risk with respect to the illiquidity return premium, which is the differential return on illiquid-minus-liquid stocks. Amihud denotes his illiquidity return premium factor by $I M L$, illiquid-minus-liquid stock return premium (see above, the discussion of Amihud, Hameed, Kang, and Zhang (2015)). The difference between the two approaches of measuring systematic risk can be illustrated by using the familiar CAPM. The systematic risk estimated by Pastor and 
Stambaugh (2003) and $\beta^{L 2}$ in Acharya and Pedersen (2005) are similar to estimating the stock systematic risk with respect to innovations in the market's monthly return volatility, $\sigma_{m, t}$, while the CAPM's $\beta$ is estimated with respect to $\left(r_{m}-r_{f}\right)_{t}$, the excess market return over the risk-free rate, which is the return premium for bearing the risk $\sigma_{m, t} \cdot{ }^{9}$ Amihud's $I M L$ has a similar role for illiquidity as the market excess return for risk. Both measure the return premium. ${ }^{10}$ Liu constructs a high-minus-low illiquidity return using non-trading days and the reciprocal of stock turnover as measures of illiquidity; turnover proxies for the stock's holding period which is related to liquidity (Amihud and Mendelson (1986)) and it is priced in the cross section (Datar, Naik and Radcliffe (1998)). Amihud constructs the factor $I M L$, the return on illiquid-minus-liquid stocks or the return on the high-minus-low quintile portfolios of stocks sorted on their ILLIQ, after having been pre-sorted by their volatility into three equal portfolios. The risk-adjusted average return on Amihud's IML for the period 1950-2012 is about 4\% annually; the four control risk factors are those of Fama and French (1993) and Carhart (1997).

Next, Amihud (2014) estimates the systematic risk $-\beta-$ of the Fama-French-Carhart factors and of IML for the Fama-French $25(5 \times 5)$ and $100(10 \times 10)$ stock portfolios, which are composed of stocks sorted on size and their book-to-market ratio. Both these variables, especially size are empirically related to illiquidity and thus can be considered as instruments for illiquidity risk. In standard cross-sectional Fama-Macbeth (1973) tests of the pricing of the factors' $\beta$, the $I M L \beta$, call it $\beta_{I M L}$, has a positive coefficient which is statistically significant for the Fama-French 25 portfolios.

This section has introduced the pricing of the systematic risk associated with illiquidity return premium or the covariance of the excess return on an asset with the excess return that investors require for holding illiquid assets. This is different from the pricing of the systematic risk associated with variations in the level of liquidity. In what follows we show that this pricing too - like the pricing of

\footnotetext{
9. Ang, Hodrick, Xing and Zhang (2006) estimate the stock $\beta$ or exposure to innovations in a factor that reflects aggregate volatility risk, proxied by VIX. They find that this $\beta$ is priced.

10. Amihud (2014) also presents estimates of the relative $I M L$, which is the $I M L$ per unit of the spread in the illiquidity between the liquid and illiquid portfolio relative to the market's overall illiquidity.
} 
illiquidity systematic risk, reviewed in Section IV - is conditional on the state of the capital market and in particular as a function of funding liquidity.

\section{The pricing of the conditional systematic risk of the illiquidity return premium factor}

Amihud (2014) proposes that it is the conditional $I M L \beta$ that is priced, where $\beta_{I M L}$ varies with the state of the funding liquidity in the market. This follows the analysis of Brunnermeier and Pedersen (2009) on the positive effect of funding illiquidity on market illiquidity and on the price of illiquidity. That is, stocks whose excess returns have greater exposure to the market illiquidity return premium in periods of funding illiquidity - on top of their regular exposure to the market illiquidity return premium - have greater expected return. The empirical formulation follows Ferson and Schadt (1996) and Ferson and Harvey (1999) where the CAPM $\beta$ is conditional on lagged macroeconomic variables whose values are known when the investors price the assets. Amihud uses as a conditioning variable the yield spread between BAA and AAA corporate bonds, which proxies for funding illiquidity. An increase in the yield spread implies greater difficulty in raising funds.

Using conditional $I M L \beta$, Amihud obtains that this $\beta$ is positively and significantly priced. That is, stocks whose $I M L$ 's systematic risk rises more when funding illiquidity is worse, have higher expected return. In a "horse race" between the pricing of the conditional IML $\beta$, both are properly priced, although the significance of the conditional $I M L \beta$ is greater and its pricing is consistent over subperiods, whereas the pricing of the illiquidity $\beta$ is not. The same results apply when using Pastor and Stambaugh's (2003) measure of illiquidity. The pricing of the conditional $\beta$ - the $\beta$ of IML conditional on the state of funding illiquidity - is stable over time whereas the pricing of the $\beta$ of the Pastor-Stambaugh (non-traded) liquidity factor is not. ${ }^{11}$

11. Notably, though, the results here are not directly comparable with those of Pastor and Stambaugh because the liquidity $\beta$ of the Pastor-Stambaugh liquidity factor is estimated here for portfolios and not for individual stocks as done in Pastor and Stambaugh (2003), and it is not instrumented. Also, pastor and Stambaugh (2003) aggregated stocks into portfolios by their instrumented liquidity $\beta$ whereas here, stocks are aggregated by their size and book-to-market ratio. 
In summary, the analysis shows that stock systematic risk associated with illiquidity is priced, when (1) this is systematic risk is measured as the exposure of the stock excess return to the market illiquidity premium excess return, and (2) this exposure is conditional on the state of the market in the sense that it is greater when the market is subject to funding illiquidity. This effect is shown to be economically and statistically significant, and it is consistent over time.

\section{Concluding remarks}

This paper presents the evolution of the models that price illiquidity. The basis for the entire analysis is that investors care about illiquidity costs and therefore price them. Amihud and Mendelson (1986) propose a model of investor's behavior which predicts that asset expected return is an increasing function of the asset's illiquidity cost, and they present empirical evidence that support this prediction. Subsequent research has presented additional evidence that supports the positive relation between expected return and illiquidity costs, both in the U.S. and around the world.

The next phase of research on the pricing of illiquidity has shown that systematic illiquidity risk is priced, where systematic risk is measured as the exposure of stock returns to shocks in market illiquidity and the exposure of stock illiquidity to the market return. This research shows that the systematic illiquidity risk is priced: the higher the stock exposure to illiquidity shocks, the higher its expected return. This research has been also extended to the pricing of corporate bonds.

The research that follows proposes that it is the conditional illiquidity risk that is priced. Research on stocks and bonds shows that in periods with benign economic and market conditions, illiquidity risk is not priced whereas in periods of adverse economic and market conditions, illiquidity risk is strongly and significantly priced.

Finally, the systematic risk associated with illiquidity is measured in a different way. Whereas earlier research examines illiquidity risk with respect to shocks in market illiquidity as characteristic, most recent research examines the systematic risk as exposure to the market's illiquidity return premium. As such, the analysis is analogous to that of the classic CAPM which measures systematic risk with respect to the market's risk premium. It is shown that it is the conditional systematic 
risk of illiquidity premium that is priced, when the conditioning variable is a proxy for the funding liquidity conditions in the market.

The study of the pricing of systematic liquidity risk is still only at its early stages. One difficulty with the theoretical analysis and empirical estimation is that they are based on a single-period holding, while Amihud and Mendelon's (1986) model shows that the effect of liquidity on asset pricing depends on investors' holding period, which is different for different investor clienteles. The resolution of this problem is a hard challenge.

Accepted by: P.C. Andreou, PhD, Editor-in-Chief(Pro-Tem), July 2015

\section{References}

Acharya, V. V.; Amihud, Y.; and Bharath, S. T. 2013. Liquidity risk of corporate bond returns: Conditional approach. Journal of Financial Economics 110: 358-386.

Acharya, V. V., and Pedersen, L. H. 2005. Asset pricing with liquidity risk. Journal of Financial Economics 77: 375-410.

Amihud, Y. 2002. Illiquidity and stock returns: Cross-section and time-series effects. Journal of Financial Markets 5: 31-56.

Amihud, Y. 2014. The Pricing of the Illiquidity Factor's Systematic. SSRN

Amihud, Y.; Hameed, A.; Kang, W.; and Zhang, H. 2015. The illiquidity premium: International evidence. Journal of Financial Economics, forthcoming.

Amihud, Y., and Mendelson, H. 1986. Asset pricing and the bid-ask spread. Journal of Financial Economics 17: 223-279.

Amihud, Y., and Mendelson, H. 1989. The Effects of Beta, Bid-Ask Spread and Residual Risk, and Size on Stock Returns. Journal of Finance 44: 479-486.

Amihud, Y., and Mendelson, H. 1991. Liquidity, maturity and the yields on U.S. government securities. Journal of Finance 46: 1411-1426.

Amihud, Y.; Mendelson, H.; and Pedersen, L. H. 2005. Liquidity and Asset Prices. Now publishing.

Amihud, Y.; Mendelson, H.; and Pedersen, L. H. 2013. Market Liquidity: Asset pricing, risk and crises. Cambridge University Press.

Ang, A.; Hodrick, R. J.; Xing, Y.; and Zhang, X. 2006. The Cross Section of Volatility and Expected Returns. Journal of Finance 61: 259-299.

Ang, A.; Liu, J.; and Schwarz, K. 2010. Using Stocks or Portfolios in Tests of Factor Models. Working paper, Columbia University.

Asparouhova, E.; Bessembinder, H.; and Kalcheva, I. 2010. Liquidity Biases in Asset Pricing Tests. Journal of Financial Economics 96: 215-237. 
Asparouhova, E.; Bessembinder, H.; and Kalcheva, I. 2013. Noisy Prices and Inference Regarding Returns. Journal of Finance 68: 665-714.

Bagehot, W. P. 1971. The only game in town, Financial Analysts Journal 22: $12-14$.

Bali, T; Engle, R.; and Tang, Y. 2014. Dynamic Conditional Beta is Alive and Well in the Cross-Section of Daily Stock Returns. Working paper, NYU-Stern.

Ang, A.; Hodrick, R. J.; Xing, Y.; and Zhang, X. 2009. High idiosyncratic volatility and low returns: International and further US evidence. Journal of Financial Economics 91: 1-23.

Brennan, M. J.; Chordia, T.; and Subrahmanyam, A. 1998. Alternative factor specifications, security characteristics, and the cross section of expected stock returns. Journal of Financial Economics 49: 345-373.

Brennan, M. J., and Subrahmanyam, A. 1996. Market microstructure and asset pricing: On the compensation for illiquidity in stock returns. Journal of Financial Economics 41: 441-464.

Brockman, P.; Chung, D. Y.; and Pérignon, C. 2009. Commonality in liquidity: A global perspective. Journal of Financial and Quantitative Analysis 44: 851-882.

Brunnermeier, M. K., and Pedersen, L. H. 2009. Market Liquidity and Funding Liquidity. Review of Financial Studies 22: 2201-2238.

Campbell, J. Y.; Grossman, S. J.; and Wang, J. 1993. Trading Volume and Serial Correlation in Stock Returns. Quarterly Journal of Economics 108: 905-939

Chen, L.; Lesmond, D. A.; and Wei, J. 2007. Corporate yield spreads and bond liquidity. Journal of Finance 62: 119-149.

Chordia, T.; Roll, R.; and Subrahmanyam, A. 2002. Commonality in liquidity. Journal of Financial Economics 56: 3-28.

Chordia, T.; Subrahmanyam, A.; and Anshuman, V. R. 2001. Trading activity and expected stock returns. Journal of Financial Economics 59: 3-32.

Datar, V. T.; Naik, N. Y.; and Radcliffe, R. 1998. Liquidity and stock returns: An alternative test. Journal of Financial Markets 1: 205-219.

De Jong, F., and Driessen, J. 2012. Liquidity Risk Premia in Corporate Bond Markets. Quarterly Journal of Finance 2 (2).

Fama, E. F., and French, K. R. 1993. Common risk factors in the returns on stocks and bonds. Journal of Financial Economics 33: 3-56.

Fama, E. F., and MacBeth, J. 1973. Risk, return and equilibrium: Empirical tests. Journal of Political Economy 81: 607-636.

Fang, V. W.; Noe, T. H.; and Tice, S. 2009. Stock market liquidity and firm value. Journal of Financial Economics 94: 150-169.

Ferson, W. E., and Harvey, C. R. 1999. Conditioning variables and the cross-section of stock returns. Journal of Finance 54: 1325-1360.

Ferson, W. E., and Schadt, R. W. 1996. Measuring fund strategy and performance in changing economic conditions. Journal of Finance 51: 425-461. 
Glosten, L. R. and Milgrom, P. R. 1985. Bid, ask and transaction prices in a specialist market with heterogeneously informed traders, Journal of Financial Economics 14: 71-100.

Hamilton, J. D. 1994. Time Series Analysis, Princeton, NJ: Princeton University Press.

Hasbrouck, J., and Seppi, D. J. 2001. Common factors in prices, order flows, and liquidity. Journal of financial Economics 59: 383-411.

Huberman, G., and Halka, D. 2001. Systematic liquidity. Journal of Financial Research 24: 161-178.

Karolyi, G. A.; Lee, K-H.; and Van Dijk, M. A. 2012. Understanding commonality in liquidity around the world. Journal of Financial Economics 105: 82-112.

Kyle, A. S. 1985. Continuous auctions and insider trading. Econometrica: Journal of the Econometric Society: 1315-1335.

Lee, K-H. 2011. The world price of liquidity risk. Journal of Financial Economics 99: 136-161.

Liu, W. 2006. A liquidity-augmented capital asset pricing model. Journal of Financial Economics 82: 631-671.

Martinez, M. L.; Nieto, B.; Rubio, G.; and Tapia, M. 2005. Asset pricing and systematic liquidity risk: An empirical investigation of the Spanish stock market. International Review of Economics and Finance 14: 81-103.

Mehra, R., and Prescott, E. C. 1985. The equity premium: A puzzle. Journal of Monetary Economics 15: 145-161.

Pastor, L., and Stambaugh, R. F. 2003. Liquidity risk and expected stock returns. Journal of Political Economy 111: 642-685.

Sadka, R. 2006. Momentum and post-earnings-announcement drift anomalies: The role of liquidity risk. Journal of Financial Economics 80: 309-349.

Stoll, H. R. 1978. The supply of dealer services in securities markets. Journal of Finance 33: 1133-1151.

Watanabe, A., and Watanabe, M. 2008. Time-varying liquidity risk and the cross section of stock returns. Review of Financial Studies 21: 2449-2486. 